\title{
Los vascos y las cadenas migratorias (1840-1880)
}

\author{
Marcelino Iriani \\ IEHS-UNIVERSIDAD DEL CENTRO
}

Desde la perspectiva teórica de la inmigración en cadena, en este artículo se analiza la inmigración de la población vasca del valle del Baztán hacia América. La singularidad del estudio es que trata el momento inicial, es decir, el escenario expulsor, no el receptor, como tradicionalmente se hace en este tipo de análisis.

Para ser un auténtico vasco se necesitan tres cosas: llevar un apellido sonoro que hable de su origen; hablar la lengua de los hijos de Aitor, y tener un tío en América... 1

\section{INTRODUCCIÓN}

\footnotetext{
unque idealizada la visión de A Lhandé no se alejaba demasiado 1 de la realidad de muchos vascos de fines del siglo pasado. Acerca de los apellidos nadie duda de la sonoridad que los caracteriza; el euskera se

${ }^{1}$ Lhandé, L'Emigration, 1909.
}

encontraba aún arraigado en muchas zonas de la región vasca y no sería sino hasta la dictadura de Franco que sintiera amenazas serias de extinción; respecto a tener un tío en América, Lhandé intentaba la friolera de sintetizar medio siglo de emigración vasca a América.

Al analizar la inmigración vasca temprana a Argentina, nuestra primera impresión coincide en parte con la de Lhandé y pensamos que el marco teórico de inmigración en cadena podría ser útil para comprobarlo. No obstante, debido a que éste se asocia al microenfoque y el seguimiento de 
grupos reducidos -recuperados desde el escenario receptor-, deberíamos esperar el resultado de varias investigaciones para pretender explicar algo o trazar tendencias acerca del fenómeno emigratorio vasco como una totalidad. Pensamos que una forma alternativa de comprobar el uso de cadena en la experiencia global de los vascos peninsulares tempranos, es la de observar el momento inicial de las cadenas, desde el escenario expulsor. Aun centrándonos en una zona pequeña, deberiamos obtener una visión de la conformación de múltiples cadenas que se bifurcan a distintos lugares de América. Observaremos pues a vizcaínos, guipuzcoanos y navarros, ${ }^{2}$ aunque concentraremos nuestra atención en estos últimos a través del análisis del valle del Baztán, entre 1840/1880.

Para los vascos tener un tío en América era casi natural; queda por ver de qué manera influyó concretamente en la decisión de los que marcharon, o si Lhandé -tal nuestra sospecha-intentaba ilustrar con esa frase la sensación de seguridad de inmigrantes que marchaban a un lugar que les era familiar desde épocas coloniales.

2 Ia clección del caso navarro para cjemplificar cl uso de las cadenas entre los vascos quizá merczca una aclaración. Daclo que cstudiamos un periodo en el que las provincias vascas pertenecian al listado español y que la identiclad cultural entre cllas (Vizcaya, Âlava, Guipúzcoa y Navarra) eran comuncs, pensamos que la elección es sustentable. Lat elección de una región del nortc de Navarra, donde aún hoy sc consideran vascos, apuntala mayormente la decisión.

\section{LAS CADIENAS MIGRATORIAS}

La cadena migratoria se ha revelado como un instrumento especialmente adecuado para restituir un puesto relevante, en el análisis explicativo, a las estrategias formuladas por los mismos grupos migrantes. Por otra parte ayuda a percibir a los movimientos migratorios no como procesos de ruptura, tal cual eran implicitamente considerados en los estudios clásicos de la década de 1860 , sino como un proceso de interacción recíproca entre el proceso de origen y el de acogida ${ }^{3}$ La mayoría de los trabajos que se ocupan de analizar este mecanismo coinciden en algunos puntos básicos, ${ }^{1}$ los que de alguna manera pueden sintetizarse en la definición clásica de John y Leatrice MacDonald:

[...] la cadena migratoria como cl movimicnto por cl cual los migrantes futuros toman conocimiento de las oportunidades laborales existentes, reciben los medios para trasladarse y resuclven su alojamicnto y su cmplco inicial, por medio de sus relaciones sociales primarias con migrantes anteriores. ${ }^{5}$

Dentro de ella, los autores señalan tres tipos de cadena posibles: la migración de varones a través de agentes laborales o "padroni"; la migración en serie de trabajadores merced a la ayuda de otros trabajadores aislados ya establecidos; y la migración con posterioridad de la familia, cuando la es-

${ }^{3}$ Devoto, listualios, 1987.

A Baily, "Cadena", 1985; Sturino, "IEmigración", 1988; Devoto, "Cadcnas", 1988.

5 MacDonald, "Chain", 1983. 


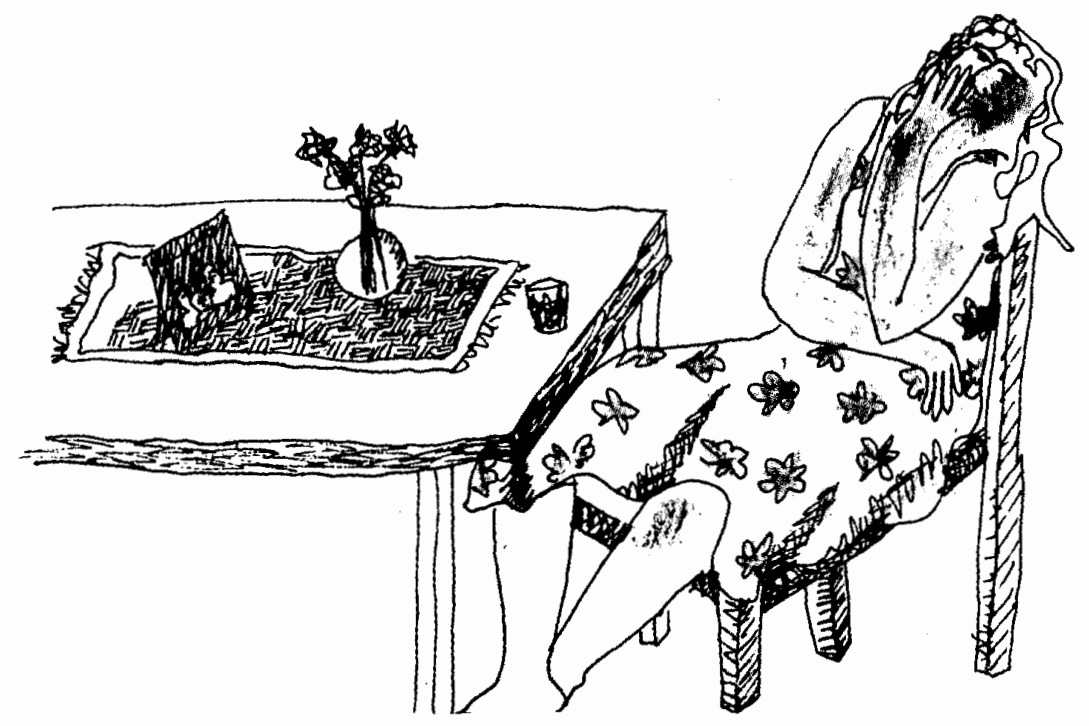

posa e hijos se unían a sus maridos que habían partido primero en busca de trabajo. Charles Price ${ }^{6}$ elaboró una tipología más amplia que incluye, dentro de la noción de cadena, la casi totalidad de la experiencia migratoria (seis tipos de cadena) por él estudiada. Intentando clarificar los límites del concepto, Fernando Devoto ha señalado que el mecanismo de inmigración en cadena es definible como un solo tipo de mecanismo migratorio y que debe ser diferenciado de al menos otros tres: $a$ ) emigración a través de mecanismos de asistencia impersonales; $b$ ) emigración a tráves de mecanismos semiespontáneos donde el proceso comienza incentivado por medio

6 Price, Southern, 1983. de informaciones parentales, paisanas o públicas, pero que el movimiento resulta del producto de iniciativas y de recursos de un individuo o de una familia aislada; $c$ ) emigración a través de padroni o de otros sistemas más difusos de mediación y clientelismo, pero donde la gestión del proceso está en manos de intermediarios externos a la cadena. ${ }^{7}$

Algunos historiadores ${ }^{8}$ se han preocupado también de alertar sobre lagunas $e$ indefiniciones en torno a este interesante aporte teórico para el estudio de la inmigración. Al margen de

7 Devoto, "Cadcnas", 1988.

8 Baily, "Cadenas", 1988; Devoto, "Cadenas", 1988; Sturino, "Emigración", 1988; Otcro, "Inmigración", 1992. 
aquellas observaciones, resulta claro que el concepto de inmigración en cadena-recuperando solamente a los llamados y ayudados por alguien- sirve para explicar un "porcentaje" de las situaciones experimentadas por cualquier grupo nacional. Se corre entonces el riesgo de convertir la teoría en un árbol que dificulte apreciar el bosque; un árbol que, por otra parte, cumple -a nuestro criterio- un papel funcional dentro del conjunto.

En el caso vasco, se puede suponer a priori` que el traslado de América abarcó los tres tipos propuestos por los MacDonald, pero también casi todos los subtipos que Devoto propone aislar como mecanismos extraños a la cadena. Una solución consiste en medir los distintos porcentajes para cada mecanismo observado y concluir sobre la forma predominante de emigrar que fue utilizada. Tomado este camino se deberá fundamentar si se dejan fuera del estudio determinados subtipos, ya que ellos también formaron parte de la realidad histórica de los protagonistas, e influyeron en sus decisiones. Nuestro criterio es que se debe repensar la importancia de la información - sin ayuda material- como motor en la decisión de muchos vascos que no deberían incluirse -según hemos visto- en el mecanismo de cadena. Si la información de oportunidades forma parte de la definición clásica de la inmigración en cadena -y es un elemento básico-, ¿por qué debe depender de elementos complemen-

9 Un "a priori" dilicil de cuantificar, pero que se relleja en casi toda la producción historiográfica existente. tarios para conformar un subtipo? $\mathrm{Co}$ mo veremos luego, las fuentes no son tan benévolas al momento de clasificar.

Ahora bien, ¿las cadenas se originan desde el escenario receptor, desde el expulsor o desde ambos? Creemos, tomando el periodo temprano, que luego de una primera oleada de pioneros, aventureros o como quiera tildárseles, la conformación de las cadenas obedeció indistintamente a llamados de los pioneros desde el nuevo lugar como a ofrecimientos de lanzarse tras ellos de los que habían quedado en sus pueblos. Pero a medida que el movimiento se intensificaba $-\mathrm{y}$ aumentaba la oferta de mano de obra y sus consecuencias-, el motor impulsor de los traspasos se instalaría en el país expulsor y no en el receptor, siendo en esta instancia cuando la información -por sobre cualquier ayuda material- se convertiría en sostenedora de un flujo continuo (quizá lentamente decreciente) de personas que emigraban apoyándose en diversas señales como experiencias exitosas, escasos retornos, cartas de paisanos a sus pueblos, etc. Esto explica, en parte, la continuidad del flujo de inmigrantes cuando han decrecido las oportunidades excepcionales de inserción. Los "padroni" y los novios y maridos se convertirían en los impulsores más visibles desde el punto de destino. ${ }^{10}$ Siguiendo esta línea argumental, y si durante gran parte del

10 Quercmos ilustrar así, que cada vez resultaría más compromctedor llamar a paisanos a un lugar doncle el trabajo había que buscirlo y cra más común cl régimen asalariado. Esto no nicga que hayan persistido invitaciones de vas- 
periodo el movimiento estuvo volcado a y desde el lugar de origen, no es intrascendente reconstruir esa etapa inicial del fenómeno. Su resultado se podrá cotejar -de alguna maneracon los estudios micro de las cadenas que se reconstruyan desde el lugar de destino.

\section{LAS FUENTTES}

Que a unos los llaman sus parientes y amigos que se hallan bien acomodados, según de público se dice; y otros se van a la aventura, persuadidos en que mejorarán de posición social o bienes de fortuna. ${ }^{11}$

Si buscamos adecuar la emigración vasca temprana a algunos de los modelos teóricos en cuestión, vemos que cualquiera de ellos refleja una parte de lo que realmente sucedió y que todas esas partes están funcionalmente vinculadas. No deben omitirse -claro está- las posibilidades de las fuentes para ello; ${ }^{12}$ aspecto descuidado de las cadenas y que puede contribuir a desalmidonar las definiciones en cues-

cos que podían emplear a quienes Ilamaban. Sólo crecmos que disminuyeron notablemente en comparación con el periodo 1855/70.

11 Estadística de Interrogación sobre Emigracion de los puchlos de Vizcaya. Obando, Zollo, 1881 , Estudios Varios, lcy. núm. 1. Archivo de Gucrnika. Respuesta del alcalde de Musques.

12 Devoto, Inmigración, p. 96, ha alertado acerca de que en las nucvas perspectivas que adquicrc el análisis de la inmigración en cadena, requicere la valorización de nuevas técnicas y de nuevas fucntes que trascicndan a los documentos públicos y a los censos. tión. En primer lugar se puede observar que, salvo excepcionales cartas de familiares, las fuentes no aclaran que el inmigrante llamado dispusiera de los elementos que indica la definición de los MacDonald. Veamos.

Si la reconstrucción de las cadenas se intenta desde el escenario receptor para el periodo $1840 / 80,{ }^{13}$ sea por la cercanía de las viviendas o el compartimiento de éstas -fenómeno que se refleja en ciertas cédulas censales-, ${ }^{11}$ la mayoria de los elementos de la definición -pasaje, habitación, alimento- son supuestos, pero no comprobables. ${ }^{15}$ Incluso la cercanía de las viviendas es una "muestra de cohesión" y de uso de la cadena -en nuestra imaginación- difícil de comprobar. ${ }^{16}$ Las investigaciones han descubierto que la cercanía geográfica se explica a partir de la adquisición de un lote - por parte de un inmigrante- cerca-

13 Cuanto más nos acercamos al presente la oferta de información es más abundante y variada. Por cjemplo la posibilidad de conscrvación de cartas y cl uso de la historia oral.

14 Por cjemplo las correspondientes al primer Censo Municipal de la ciudad de Buenos Aires, 1855, ^GN. Al presentar datos como pueblo de origen, años de residencia y alinidad con c] propictario o encargado de cada vivicnda, sc pucde comprobar - parcialmente- el ritmo $y$ los intervalos de supuestas cadenas, como asi también si la composición de las probables cadenas son de padres e hijos, entrc, primos, etcétcra.

15 En una publicación reciente, Otcro, "Inmigración", 1992, reconstruyc cadenas a través del uso de fucntes de información parroquiales y civiles.

16 Las biogralias e historias de vida permiten comprobar el uso del mecanismo, pero se trata de unos pocos casos y generalmente de aquellos que lograron "éxitos" sobresalientes. 
no a la vivienda donde residió en un primer momento. ${ }^{17}$ Pero las fuentes no explican que ese inmigrante residiera gratuitamente en aquella vivienda de paisanos. Se puede pensar, que si bien pudo permanecer unos días, luego -fuera pariente o no- comenzaría a pagar cama y comida, o devolver el favor con trabajo. Esta suposición se apoya en una investigación reciente que hemos realizado, cuando buscábamos los origenes de las fondas vascas en la provincia de Buenos Aires. ${ }^{18}$

Los registros parroquiales, a través de los casamientos, también permiten presuponer el uso frecuente del mecanismo de cadena entre los vascos. Tomando, a modo de ejemplo, los participantes de los enlaces llevados a cabo en Tandil entre 1852 y 1882 , vemos que: entre los 137 vascos -cónyuges varones- hay 21 grupos de apellidos con igual nacionalidad; mientras que entre las 143 esposas encontramos 22 grupos de apellidos con idéntica nacionalidad. En pocos casos contamos con el nombre del pueblo de origen, pero aunque lo obtuvieramos nos faltarían datos que prueben que traspasaron utilizando el mecanismo en cadena. Se puede suponer -en determinados casos- que así lo hicie-

\footnotetext{
17 Véasce Baily, "Patroncs", 1985; Wcinberg y Fiberlc, "Abruzcses", 1988 o Sillocrstcin, "Inmigración", 1988.

18 Notábamos allí, que la gran mayoría surgió a partir de casas de lamilia que subarrenciaban piczass a connacionales -lénómeno natural en cl País Vasco-y que en un momento dejaron la clandestinidacl para transformarse en pequeñas empresas fanniliares. Véasc Iriani, "Como", 1993.
}

ron, pero no comprobarlo. Estas fuentes -de reunión de inmigrantes paisanos en lugares específicos de Américaapuntalan mayormente el uso de información. Información que no debe entenderse únicamente como un canal entre un punto receptor y otro expulsor, sino como algo mucho más complejo. ${ }^{19}$ Probablemente, muchos inmigrantes salieron de sus pueblos con unos pocos e imprecisos datos sobre un destino (geográfico o familiar), mismos que se fueron constatando o modificando a través de otros datos obtenidos en el puerto de embarque, durante el viaje, en Montevideo, Buenos Aires, el Asilo de inmigrantes, etc... o sea, en todo el trayecto recorrido hasta la zona nuclear planificada. Pero en ese recorrido algunos pudieron encontrar una oportunidad mejor, otro amigo o familiar o una pareja. Al respecto hemos encontrado en la revista La Vasconia (1893/99) innumerables avisos de vascos que desean ubicar a un familiar que en tal fecha trabajaba de panadero en un determinado lugar. ${ }^{20}$

En la etapa masiva -que no es nuestro objetivo- el número de fuentes se amplía y diversifica: registros de miembros de sociedades de socorros mutuos; actas matrimoniales de Registro Civil; periódicos étnicos y, principalmente, entrevistas a los propios actores.

Desde el escenario expulsor la información varía en cantidad y calidad pero -salvo excepciones- tampoco se comprueban los elementos en cues-

19) Al respecto resultan interesantes las observaciones de Baines, Migralion, 1985.

20 Véase La Vasconia, 1893-1899. 
tión, ${ }^{21}$ que resultan fundamentales para la atomización de las categorías de cadena y la exclusión de mecanismos "indefinidos". Las declaraciones protocolares ante el notario, las encuestas a los alcaldes y la literatura de la época evidencian la existencia masiva de llamado de familiares, pero salvo la presencia de remesas, ${ }^{22}$ tampoco reflejan las ventajas en cuestión. El llamado de familiares pudo haber sido en ocasiones una carta llegada al caserío que reflejaba el éxito de los que se fueron. Inclusive la declaración de ser llamado por un pariente, pudo ser idealizada para demostrar cierta factibilidad de éxito entre los que necesitaban que se les adelantara el pasaje y contaban con garantías modestas. ${ }^{23}$ También se puede suponer una fuerte carga psíquica en el migrante al abandonar su lugar para marchar a un futuro de cualquier manera incierto. Por un lado, su actitud lo convertía en rebelde ante un sistema que no le brindaba mayores posibilidades de progreso; incluso ante los enemigos del carlismo. La partida era un signo evidente de intransigencia con las reglas de juego, lo que lo reivindicaba parcialmente ante el resto. Pese a es-

21 Otcro, cn "Inmigración", 1992, remarca la importancia de las fucntes, sobrc todo la falta de cllas, para cualquice intento de reconstrucción de las cadenas desdc cl ámbito expulsor.

22 las remesas podian utilizarse para innumerables actividades, y es posible que con la posibilidad concreta de pagar el pasaje en el nucvo lugar durante un año, no fuera una buena cstrategia abonar de contado.

23 Otero, en "Innigración", 1992, agrcga quc la llamada del exterior lenía -al menos en partela cvidentc función idcológica de trasladar las causiss de la cmignación al otro laclo del $\Lambda$ tántico. to, en un lugar donde el auzolán (trabajo de vecinos) era una regla básica, marchar a la deriva podía significar un desaire para quienes lo habían alimentado hasta ese momento. El anuncio de marchar a un lugar determinado y contar con oportunidades excepcionales, alivianaría la carga de culpa. El frecuente anuncio de envío de remesas o de regresos triunfales para ayudar "a todos", ocultaba mal las angustias de cada emigrante al romper con los suyos.

La declaración de ir a donde un familiar pudo obedecer también a otras diversas razones, por ejemplo, presión de los padres para convencer a las autoridades antes de embarcar a un menor. "Ir a Buenos Aires donde vive un hermano desde hace unos años", frase común en los protocolos notariales, ${ }^{24}$ pudo referir frecuentemente a estas situaciones. La lectura de los protocolos notariales del Baztán, que analizamos más adelante, muestra un número importante de casos que "se dirigen a Buenos Aires donde se encuentran sus hermanos o parientes o tíos", etc. Queda una duda: querían encontrarse con sus parientes o, como éstos continuaban allí -reflejo de cierto progreso-, escogian dicho destino. ${ }^{25}$ Ahora bien, si las fuentes decimonónicas vascas no

21 Por otra partc la gran mayoria de las declatacioncs reflejan ir a y no ser llamado por, lo que hace más confuso aún el uso de definiciones rígidas en el caso vasco.

25 Pesc a la crítica a la que somctemos las luentes, no podemos dejar de reconocer que un porecentaje de cualquicr grupo nacional recibió alguna ayuda matcrial concretit. las críticas apuntan a obscrvar quc csa ayuda matcrial 
apuntalan claramente los subtipos de los MacDonald y es posible que un porcentaje de la información estuviera falseada: ¿se debe descartar el estudio del uso del mecanismo y sus efectos desde el escenario expulsor para este grupo nacional? Creemos que no. Si las fuentes no conllevan a una comprobación cuantitativamente rigurosa, pueden, no obstante, reflejar el uso del mecanismo y quizá el trazado de tendencias. De este modo, las encuestas a los alcaldes y principalmente los protocolos notariales ${ }^{26}$ sirven como fuente de información cuantitativa $y$ en mayor grado cualitativa. ${ }^{27}$

posible está tan ausente de las fuentes como lit información.

26 los protocolos notariales están siendo actualmente relevados en las tres provincias vascas peninsulares. Esta tarea, que demanda años de trabajo en archivos, ha sido iniciada por Ángel Rodriguez para Álava y Carmenbeatriz Herrera, para Guipúzcoa, ambos becados por la Comisión Quinto Centenario América y los vascos. Dos trabajos anteriores han sido el de Idoate Exquieta para el valle del Baztín en Navarra, "Emigración", 1989; Pildain Salazar también para Guipúzcoiı, "Ir a América". Por su parte Álvalro San Román, también becado por Quinto Centenario, espera la reapertura del Archivo Protocolar de Vizcaya (cerrado hace cuatro años) para efectuar el relevamicnto. Salvo el caso de Idoate lisquicta, el resto del estado de la cuestión fixe obtenido por conversaciones personales mantenidas con los investigadores mencionados en Fuskadi, octubre-noviembre de 1991.

27 Los protocolos notariales retlcjan únicamente la cmigración legal. Por esto, o mejor dicho, por la gran masa de vascos que emigraba clandestinamente, no se convierte cn una fuente que garantice la reconstrucción total de lia experiencia. La salida clandestina no sugicre, en ningún caso, que se tratara en mayor o menor medicla de personas que estaban utilizando el mecanismo de cadena o no.
Creemos que con los datos actuales se pueden reconstruir, a modo de muestreo, las tendencias en cuanto a la emigración en cadena desde Euskadi entre 1840 y $1880^{\circ}$, al igual que el efecto de la información sobre el conjunto.

En el caso de los vizcaínos, sobre 101 respuestas extraídas de la Estadística sobre emigración de los pueblos de Vizcaya (1881), ${ }^{28}$ se deduce que treinta $(29.71 \%)$ marcharon llamados por parientes o amigos; treinta y dos (31.69\%) para mejorar fortuna; dieciocho $(17.82 \%)$ para dedicarse al comercio; mientras que el $20 \%$ restante aparece repartido entre evitar el reclutamiento, como pastor, no tener trabajo en el pueblo, a la aventura, etc. Leyendo detenidamente las respuestas de los alcaldes a dicho interrogatorio, queda claro que los funcionarios sabían que el gran imán era el conocimiento de lo que sucedía en América, aunque en algunas respuestas se intente desmitificarlo o empañarlo por la visión falsa brindada por los agentes enganchadores. De 34 respuestas que afirman que la causa principal de emigración de su pueblo es el llamado de parientes o amigos de ultramar, se pueden extraer algunas conclusiones. Pocas respuestas, como la del alcalde

28 Ia circular contienc una plantilla con cinco preguntas básicas para ser completadas por los alcildes que a continuación abreviamos: 1) Los habitantes cmigran liucra del territorio espanol 0 a otras provincias. 2) lin caso de ir al extranjero, iqué catusa la produce? 3) Númcro anual cle cmigrantes del último quinquenio, clasilicado por scxo, cdad y destino. 4) Si van a otras provincias de España, zen qué ćpocas se realizan? 5) idecorren esa localidad agentes de cmigración? 
de Guerricaiz, reflejan claramente un puesto de trabajo en el nuevo lugar:

El primero [marcha] por haberle llamado un tío de Buenos Aires para que fuera allí y trabajara en su compañía en el oficio de pastor de ganadería. El segundo y el tercero, hermanos, también por haberse dispuesto que fueran al puerto llamado Buenos Aires por un tío que está establecido en aquel punto para que le acompañara en el ejercicio de pastor a trueque de ganancia. Fl cuarto, también avisado al mismo país de Buenos Aires, por un tío en concepto de pastor.

Lo que es notable en el conjunto de las respuestas, es que diez de ellas combinan ir "ande sus parientes a dedicarse al comercio", lo que permite inferir que acaso ese ramo fuera el que mayormente permitía hacer un lugar laboral a un paisano. Otra tendencia a punta a que, cuando marchan mujeres, "van ande sus tíos" mientras que los hombres van indistintamente al encuentro de hermanos o tíos.

Tomando como fuente otra respuesta de funcionarios, los mandatarios del Ayuntamiento de Lesaca veían ya en 1868 , que lo que predominaba en todo aquello era el llamado de familiares:

Los cmigrantes no habían dejado sus pueblos por lalta de trabajo $[\ldots]$ el motivo principal de la ida de padres, hijos, parientes y amigos es que se convalachan [sic] unos con otros, abandonando con facilidad sus hogares, sus pucblos y haciendas, después que las han cubicrto de deudas y burlado completamente la buena fe de los deudores [además] las halagüeñas noticias que esparcen los especuladores, conductores en cl sentido de que todos los que han ido están perfectamente colocados, trabajan y ganan mucho, hasta una, dos y más onzas de oro mensuales, y que pueden ahorrar mucho teniendo como ticnen el alimento de carne casi en balde. ${ }^{29}$

Esta cita es elocuente -el momento era bueno en América - en cuanto a la red que actuaba para la partida, pero también respecto a la falta de impedimentos para emprender el viaje, no vacilando, entre otras cosas, en endeudar varios el mismo inmueble. Los funcionarios dudaban (ver la cita que da comienzo a esta parte del artículo), de que realmente fueran a encontrarse con parientes y amigos e incluso que aquellos estuvieran "bien acomodados"; sobre lo que no tenían dudas era sobre la persuasión de mejorar que se observaba en los que marchaban sin ser llamados.

Los protocolos notariales se presentan como una fuente muy interesante, y que puede remediar buena parte de los huecos que la información oficial ofrece hasta $1881 .{ }^{30}$ Por ahora contamos con adelantos para Guipúzcoa y una zona concreta de Navarra. En esta última, en 812 proto-

29 Respucsta de lcsaca a la Circular conviada por la Diputación de Navarra en 1868 (BON), tomada de Virto, "Emigración", 1991.

${ }^{30}$ La última cesión de Protocolos Notariales del Ilustre Colcgio Notarial de Pamploma al $\wedge G N$ fuc en novicmbre de 1980 . Por cso ba documentación analizada por Idoatc lizquicta linaliza con 1879 , pucs sc manticnc una valide\% de 100 años en poder de los notarios. 


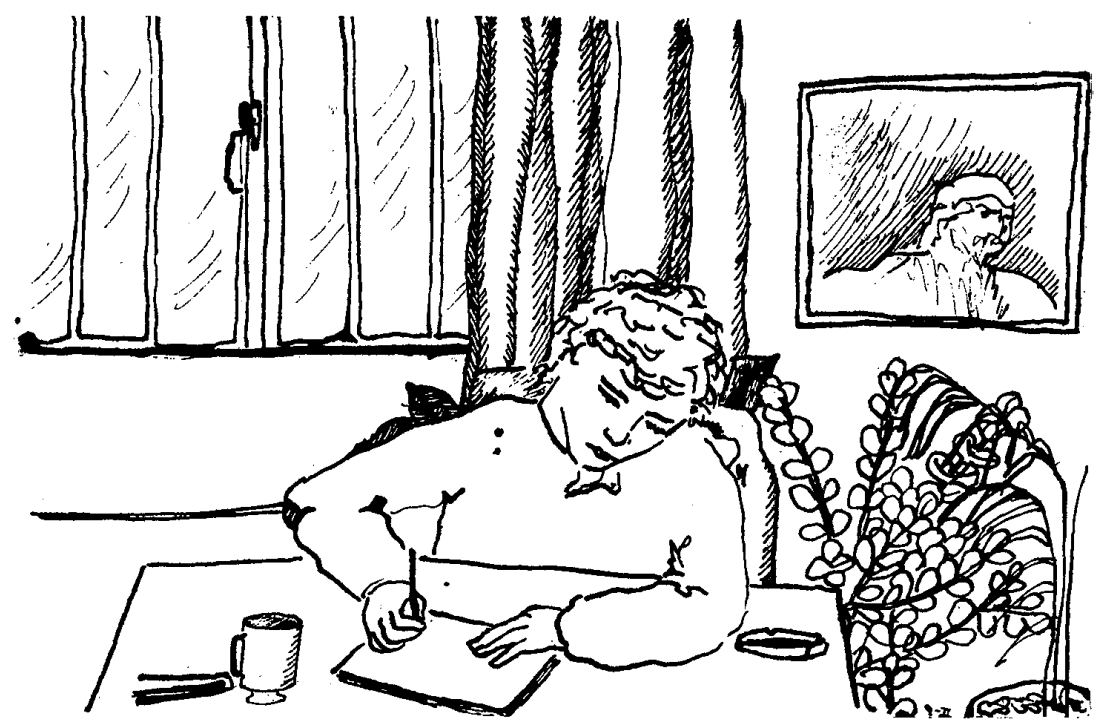

colos notariales ${ }^{31}$ sobre emigración del valle del Baztán, 555 declaran marchar a mejorar fortuna (68\%); 189 llamados por parientes (23.27\%); otros 40 por fortuna y parientes (4.93\%); 12 más, por trabajos convenidos previamente $(1.48 \%)$ y los 16 restantes a trabajar indistintamente (8), al comercio (7) y administrar hacienda (1). ${ }^{32} \mathrm{La}$ confianza es tal, por otra parte, que Pedro Maritorena y su mujer Antonia Mutuberria, vecinos de Elizondo (Navarra), otorgan consentimiento a su hijo Miguel, para que vaya a Cuba, a

31 los correspondicntes a Conscintimicutos y fianzas en Jdoatc, Emigración, 1989, apéndice doc.

32 Jdoatc, Emigracion, 1989, p. 26. trabajar en lo que le "proporcionen sus amigos y conocidos". .3

Pilar Pildain Salazar, volcada al estudio de los guipuzcoanos, extrajo idénticas conclusiones con base en el estudio protocolar de dos oleadas: la primera-1840/42-donde emigmn 1300 personas; y la segunda -1852/70donde lo hacen 1 100. La autora confirma el peso que tuvo el llamado de familiares, y lo mismo el incentivo de mejorar económicamente, frecuentemente mencionados como causas para emigrar. Dentro de los 2400 emigrados-legales-, entre 1840 y 1870 , hemos tomado el caso de Oñate como ejemplo. Ubicado al interior de la pro-

33 I'crmin Arizcun Ariztcgui, carp. 26, núm. 260, cn Idoatc, Emigracion, 1989, p. 254. 
vincia de Guipúzcoa, parten de allí 208 personas hacia Buenos Aires y Montevideo, conformando 26 grupos de apellidos que encierran 106 personas. Lo importante de este centenar de vascos que marchaban hacia América para encontrarse con familiares, al margen de saber si tendrían habitación o comida asegurada, es que eran transmisores de que América era posible hacia el resto de las personas. Así, la "seguridad" de éstos era tomada por el resto como un reaseguro, $y$ actuaba fuertemente en la decisión de emigrar ${ }^{34}$ En este sentido, la información se convierte en un elemento funcionalmente decisivo y actúa a la par de otros elementos materiales concretos. ${ }^{35} \mathrm{El}$ aspecto mental y traumático de la decisión era -a nuestro criterioun obstáculo tan importante como el pasaje, el alojamiento o un trozo de pan asegurados. Pensamos que un efecto importante sobre la funcionalidad del mecanismo se encuentra precisamente en lo afectivo, aspecto un tanto descuidado en los trabajos que reconstruyen experiencias migratorias. Contar con un familiar o amigos sería evidentemente de gran ayuda para enfrentar un ambiente, una cul-

${ }^{34}$ Aunque parezen algo obvio, es destacable el hecho de que el resto marche también a Buenos Aires y Montevideo y no a Álicica o Jamaica. Respecto al papel funcional de la información y cl grado de racionaliclad en la clección del destino, es notable que hacia $1870 / 80$ aparezca una desviación importante hacia cl oeste americano y hacia 1920/30 hacia Australia.

35 Otcro en "Inmigración", opinat que aun en el caso de que las redes sociales no impliquen formas concretas de ayuda, no dele subest imarse la importancia que la transmisión de informaciones tenía en la época. tura y un idioma distintos. Caer en desgracia a diez mil kilómetros de casa no era una posibilidad remota, casi lo contrario. Accidentes de trabajo con secuelas de invalidez, muerte de seres queridos, ruina por emprendimientos comerciales desfavorables, eran posibilidades que hacían indispensable a alguien en quien apoyarse. Desde 1876 , los vascos que residieran cerca de la ciudad de Buenos Aires podian contar con recursos para regresar o paliar alguno de los tropiezos mencionados por medio del Centro Vasco Laurak Bat. De todos modos, es probable que la gran mayoría de los emigrantes vascos a la provincia de Buenos Aires, pronto encontrara paisanos en cualquier punto de ella; ${ }^{36}$ además de que muchos de ellos trajeran -aunque no fueran invitados- direcciones de paisanos para ubicar. ${ }^{37}$

Una última reflexión respecto a las fuentes escogidas es que, en todos los casos, el número de los que declaran ir a mejorar fortuna -indicio de conocimiento/información - es notablemente mayor al de los llamados por alguien.

36 Abunda la litcratura que refleja rcuniones de vascos en fondas $y$ hoteles (gencralmente atcndidos por vascos), que nos brindan indicios sobre la rápida ambicntación del recién lleyaclo: Torassa, Particlo, 1940; Garciarena, Carlas, 1977; La Vasconia (1894-1899) (col. revistas).

37 Iin 1882, cuando llcga doña Joscla Olariaga, la recibc Antonio Iraz, que por esc cnton ces cra uná especic de cónsul de los vascos en Bucnos Aircs. Sarasola, que cumplía jugal pape] que éste pero cn Tolosa, solía recomendar a sus clientes que, si en Buenos Aires no tenían a nadic, sc dirigican a D. Irazu. Garaico Echea, Vasconia, 1945. 
EUSKAL HERRIA

El ejemplo de una fortuna rápida, 50000 francos, penetró de boca en boca hasta el último rincón de la zona vascofrancesa.

P. Barrere (1842).

Hemos visto en trabajos anteriores, ${ }^{38}$ que la Euskadi decimonónica sufría distintos procesos que motivaban la partida de sus habitantes, como el avance de nuevas ideas y métodos productivos que acorralaba lentamente a campesinos y artesanos, al que se sumaron dos guerras perdidas, y que fueron sin duda causas importantes; pero las oportunidades en ultramar, como los diferenciales de ingreso, una posibilidad de progresar rápidamente, aparecen como los verdaderos motores de la partida durante la etapa temprana. Los vascos no huían de la miseria, sino atraídos por la posibilidad de estar mejor en otro lugar. La atmósfera que se respiraba a ambas laderas de los Pirineos entre 1840 y 1880 , era la de una sensación esperanzada de seguridad para cruzar hacia América. Los trabajos de Louis Etcheverry, ${ }^{39}$ Paul Barrere, ${ }^{40}$ George Viers, ${ }^{41}$ entre otros, advierten asimismo sobre los diferenciales de ingreso y la llamada de parientes como causas de la partida entre los vascos franceses.

Primaban, en definitiva, los efectos de atracción sobre los de expulsión y la gente se sentía incluida -de alguna

38 Iriani, "Vascos", 1994.

39 Etcheverry, "Basques", 1886.

to Barrere, Emigration, 1842.

4 Vicrs, "Chronique", 1957. manera- dentro de una gran "cadena migratoria". A primera vista, entonces, el caso vasco estaría mayormente comprendido por la "indefinición tipológica" de Price, precisamente porque - tal la crítica de Devoto- distingue poco entre la cadena migratoria y otros mecanismos migratorios convirtiendo a aquélla virtualmente en el único procedimiento existente y trasladando el centro del mecanismo de la cooperación a la información. ${ }^{42}$

Cuando alguien de Arizcun se iba a Buenos Aires con una parte de su futuro "solucionado" (provocando un rumor general de cuánto ganaría, en qué ocupación faltaba gente y dónde residiría) y tras él lo hacía alguien que no era llamado por nadie, no existían diferencias sustanciales entre ambos, al menos en el periodo temprano. Por un lado, el dinero para el pasaje que recibió el primero, el segundo podía conseguirlo a través del adelanto del pasaje, ${ }^{43} \mathrm{e}$ incluso por la parte que le correspondía como segundón. En cuanto al alojamiento, éste podía ir al Asilo de inmigrantes, pero también compartir la habitación temporalmente con el que se marchó tiempo antes - sin estar apuntado en las fuentes-o buscar el domicilio de otros paisanos.

42 Devoto, "Cadenas", 1987.

13 Existc abundante bibliogralia sobre cl papel de los agentes en el País Vasco, y sobre la lacilislad de conscguir el pasajc para América. Incluso contamos con documentos de juicios dilatados de pasajes impagos que terminan sin cobrarse. Para el papel de los agentes ver: Pildain, Ir a América, 1991; Idoatc, Lmigración, 1989; Douglas y Bilbao, Amerikanuak, 1986; Azcona, "Torno", 1988. 
En cuanto al trabajo, el primero pudo haber recibido tanto la invitación a insertarse específicamente como empleado del comercio de un tío, como a iniciarse en un saladero de Barracas al Sur "donde abundaba el trabajo". Los efectos de la noticia son diferentes en uno y otro caso para el resto de la aldea. Pero lo que mayormente equilibra las posibilidades de ambos inmigrantes, es que no existen pruebas de que la reunión con un familiar fuera sinónimo de obtención de pasaje, vivienda y comida. Que un inmigrante llamara a su novia o familiares directos era natural y existen cientos de ejemplos similares en todas las épocas del devenir humano. Lo trascendente, a nuestro criterio, es ver que ese gran entrecruzamiento de información, ayudas y rumores fuese el motor del pase de miles de personas a lugares específicos del planeta.

Respecto al área geográfica de influencia de la información, que no necesariamente debe entenderse por aquella en la que prevalecían las relaciones sociales primarias, creemos que los vascos aportan elementos interesantes de análisis. Franc Sturino ha propuesto con criterio que, en determinadas condiciones, un área social de diez kilómetros de radio de influencia de las relaciones primarias de la cadena, es más apropiado que el área de la aldea o la provincia. Sin embargo, si se tiene en cuenta el papel hilvanador de pastores o pescadores -brindando peso al papel funcional de la información-y si los círculos de acción de las redes sociales se juntan, puede pensarse que Vizcaya y Guipúzcoa fuesen casos puntuales de que, en ciertas circunstancias, la provincia era una área de influencia probable. Existían canales de difusión efectivos para las noticias: las mujeres de los pescadores -en Guipúzcoa, Vizcaya o Laburdi- caminaban diariamente hasta $25 \mathrm{~km}$ hacia el interior a vender sus pescados, mientras que los pastores recorrían en estaciones toda la región desde los pastos de verano a los de invierno, y durante el año en recorridos más restringidos.

Todas las aldeas tenían el conocimiento de lo que pasaba. Tampoco debe olvidarse que pocas naciones tienen un calendario de fiestas - regionales - tan abundante como Euskadi. Las noticias se difundían también a partir de medios menos informales como los utilizados por los agentes de viajes. Para analizar qué sucedía en un espacio social más reducido, veremos también el valle de Baztán.

\section{Del. valle de Baztán a Buenos Aires}

El valle del Baztán se encuentra en la zona más septentrional del partido, judicial de Pamplona, ocupando el cua. drante NO de la provincia de Navarra. Es un valle enclavado en plena montaña, en medio de los montes que forman el arranque de la cordillera pirenaica. Con un perímetro de unos 100 $\mathrm{km}$, alcanza una superficie de casi 275 $\mathrm{km}^{2}$. Esta superficie contiene catorce núcleos tradicionales de población. Cada pueblo cuenta además con algunos barrios y grupos de caseríos que no llegan a la categoría de barrio. El eje principal lo forma el río Baztán, que se convierte en el Bidasoa al aban- 


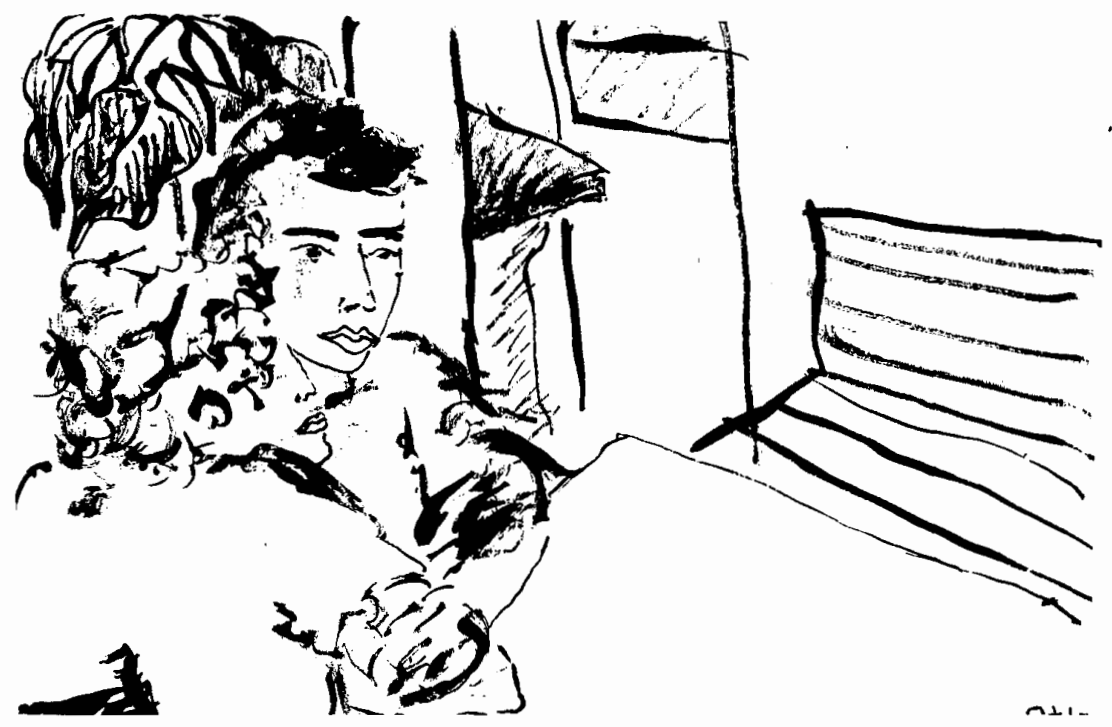

donar el valle. ${ }^{\text {Ai }}$ La población aproximada del valle entre 1840 y 1880 era de 8500 personas. ${ }^{45}$

El clima es típicamente oceánico, muy húmedo todo el año y con escasa oscilación térmica. Esto permite una dedicación a una agricultura intensiva en el llano, agricultura de escasa importancia, más bien de supervivencia, cosecha para la casa o complementaria del ganado. Este último ocupa gran parte de los numerosísimos prados; el aprovechamiento forestal y minero ha sido importante también para la economía de los vecinos del valle, al me-

4 Para tener una relierencia del espacio de funcionamiento de las redes sociales, entre lilizondo y Oronoz (ocstc) median $12 \mathrm{~km}$ y contre Elizondo y Maya (norte) $14 \mathrm{~km}$.

45 Idoatc, limigracion, 1989. nos hasta el siglo pasado. Respecto a las comunicaciones con el valle éstas presentan relativa dificultad; en el siglo pasado existían pocos medios para avanzar rápidamente, $y$ accidentes geográficos que atravesar. ${ }^{16}$ Dentro del valle existía un fuerte sentimiento de vecindad, autosuficiencia y pertenencia al mismo. ${ }^{17}$ La ganadería, el producto fuerte del valle, lo ligaba cada estación a otras regiones de Navarra, cuando los pastores se veían obligados a conducir su rebaño de la nieve a la ribera. ${ }^{48}$

${ }^{46}$ Hidl., p. 15.

47 Toda la ticrra que no pertenceía a nadic en particular cra de tólos. Que Baztán signifiquc todos son uno, habla por sí solo.

48 Gallego, llistoria, 1982. 
Mapa. Valle del Baztán

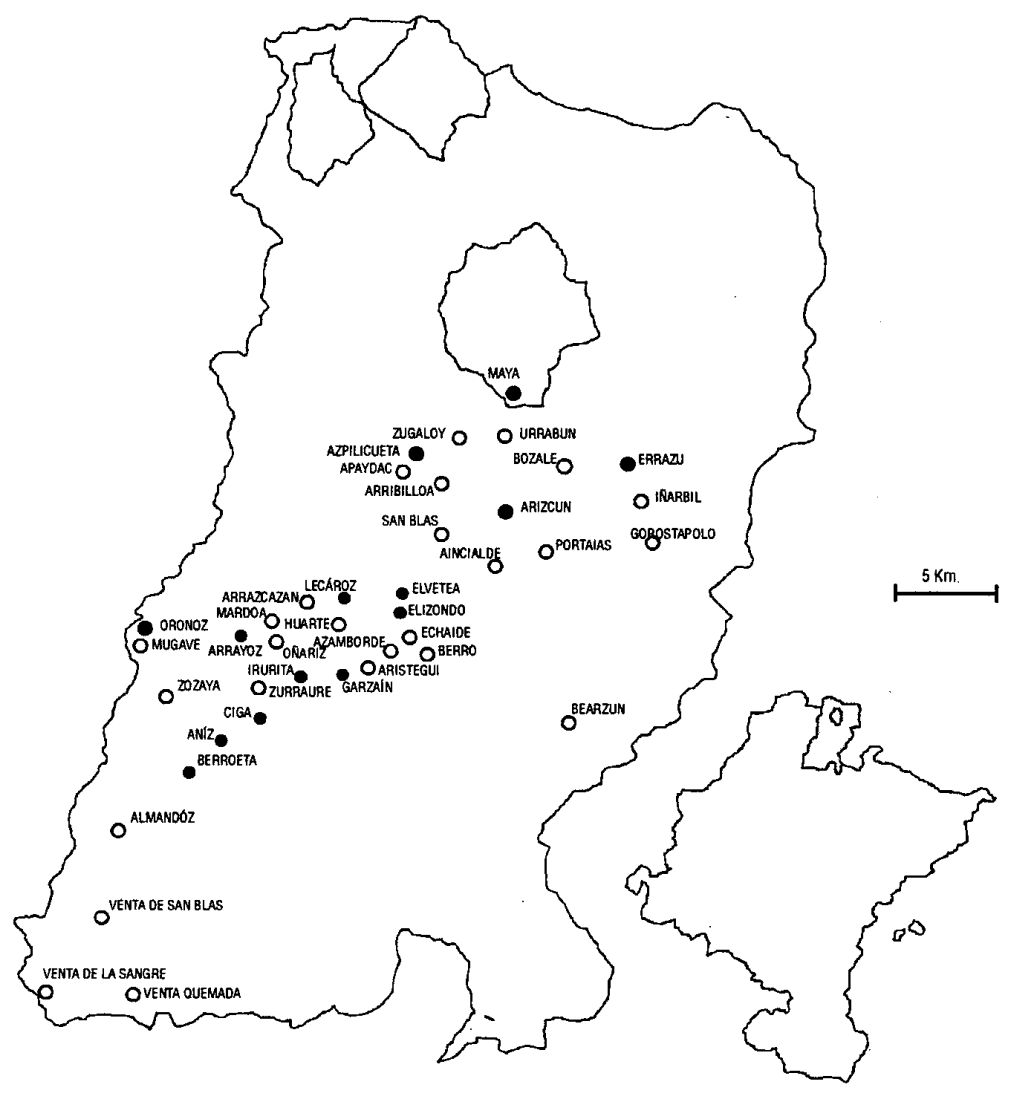

Fuente: Carlos Idoate Ezquieta, Emigración, 1989, p. 13. 
Hemos analizado 1903 protocolos notariales reunidos por Idoate Ezquieta en el apéndice documental de su trabajo ya mencionado. Éstos se dividen en legajos de Consentimiento y Fianza $^{49}$ (862); Obligaciones ${ }^{50}$ (405); Contratos de Viaje ${ }^{51}$ (168) y el resto de aquellos que sin estar ligados a la inmigración estaban relacionados con América (testamentos, poderes, herencias, etc.) Los emigrantes no coinciden con el número de expedientes, ya que en varias oportunidades se realizó el trámite grupalmente. Cabe recalcar que hemos tomado solamente aquellos casos en los que se mencionaba llamado o encuentro con alguna persona en el lugar de destino. Para los 276 casos en cuestión se tuvo en cuenta el pueblo de origen; apellido y nombre del emigrante; edad y profesión (no figura siempre); destino; y cadena (persona/s a la que iba a encontrar). La casi totalidad de los casos que encontramos surgen del primero

49 Los documentos conocidos como fianzas no aparecen hasta 1863 , hecho que se puede fundamentar con el cambio de notario, que introduce nuevos formulismos; de todos modos no cambian mayormente en cuanto a estructura y contenido de los consentimientos que regían hasta ese momento. Si el consentimiento paterno o del tutor del muchacho es básico para que éste consiga la emancipación, no lo es menos el pago de la fianza, que libraría a los futuros emigrantes de la carga de realizar el servicio militar, en caso de tocarles en el sorteo.

50 Dan comienzo en 1840 y terminan en 1872 , donde comienzan a confundirse con los llamados consentimientos. Quizá el dato más interesante que brinda es el referente a compañías y comisionados.

51 Se encuentra entre 1840 y 1866 , notándose un vacío documental entre 1843 y 1851. de los documentos, pero los diferentes totales utilizados (pueblo de origen, destino, emigrantes por año) se obtienen de la suma de todos ellos.

Un dato importante lo constituyen los elevados porcentajes de quienes se marcharon dentro de alguno de los tipos de cadena dentro del total de emigrantes de cada pueblo. El promedio general (30\%) muestra un porcentaje elevado de emigrantes que marcharon con un "destino más o menos cierto". Precisamente utilizamos esta categorización, porque todo hace suponer que el enunciado ante el notario era más una frase que una certeza en los beneficios que el migrante recibiría.

De los 276 casos, 92 declaran ir al encuentro de hermanos/as; 12 del padre; 39 de parientes; 48 de tíos/as; 5 de tíos y otros; 4 de maridos; 4 de primos; 1 de un amigo y 59 al encuentro de una persona concreta, con nombre y apellido.

La lectura de las cifras indica que los hermanos y tíos - ya que la cifra parientes seguramente encierra mayormente a tíos-fueron quienes más inmigrantes movilizaron. Lo notable de las 59 personas que van a encontrarse con alguien en especial, es que aquellos que los esperaban eran unos pocos. Anselmo Zurutusa (México); al igual que M. Marticorena, P. Gortari, J. Inda y Martin Urdaniz (La Habana); seguramente eran grandes comerciantes, cultivadores $O$ industriales que solventaban el pasaje y esperaban con trabajo a los inmigrantes vascos. Curiosamente -o no- no aparecen personajes similares para Montevideo o Buenos Aires. 
Cuadro 1. Porcentaje de emigrados dentro de cadenas

$\begin{array}{lccc}\text { Pueblo } & \begin{array}{c}\text { Total } \\ \text { emigrantes }\end{array} & \begin{array}{c}\text { Emigrantes } \\ \text { en cadena }\end{array} & \text { Porcentaje } \\ \text { Almandóz } & 40 & 6 & 15.00 \\ \text { Aniz } & 18 & 6 & 33.33 \\ \text { Arizcun } & 235 & 43 & 18.29 \\ \text { Arrayoz } & 99 & 25 & 25.25 \\ \text { Azpilicueta } & 45 & 3 & 6.66 \\ \text { Berroeta } & 43 & 7 & 16.27 \\ \text { Ciga } & 79 & 26 & 32.91 \\ \text { Elizondo } & 182 & 37 & 20.32 \\ \text { Elvetea } & 76 & 9 & 11.84 \\ \text { Errazu } & 146 & 12 & 8.21 \\ \text { Garzaín } & 107 & 17 & 15.88 \\ \text { Irurita } & 137 & 30 & 21.89 \\ \text { Lecároz } & 110 & 22 & 20.00 \\ \text { Oronoz } & 65 & 21 & 32.30\end{array}$

Cuadro 2. Emigrados en cadena y destinos

$\begin{array}{lccc}\text { Destino } & \begin{array}{c}\text { Núm.de } \\ \text { emigrantes }\end{array} & \text { En cadena } & \text { Porcentaje } \\ \text { Cuba } & 156 & 86 & \\ \text { México } & 40 & 18 & 55.12 \\ \text { Montevideo } & 217 & 26 & 45.00 \\ \text { Buenos Aires } & 969 & 126 & 11.98 \\ \text { Mues } & & & 13.00\end{array}$

Otro dato importante surge de los porcentajes de emigrantes en cadena sobre el total de emigrantes a cada destino.

En los dos sitios que marcamos como de mayor uso de la emigración a través de padroni, los porcentajes son notablemente más elevados que en Buenos Aires o Montevideo. Así mismo los guarismos para América del sur son sumamente importantes.

Si observamos los momentos de mayor emigración de baztaneses y los comparamos con los picos de emigrantes en cadena, notamos que coinciden.

La relación de habitantes entre $1852 / 57$ de los pueblos de Baztán ilustra sobre el estancamiento e inclusive retroceso demográfico experimentado por la mayoría en ese quinquenio, lo que demuestra la homogeneidad de la partida desde todos los puntos del valle. En el mediano plazo, y tomado el conjunto del valle, la pérdida poblacional es significativa, pasando de 
Cuadro 3a. Número de emigrantes totales por año, 1840/1879

$\begin{array}{lrrr}\text { Año } & \text { Núm. } & \text { Año } & \text { Núm. } \\ 1840 & 33 & 1857 & 34 \\ 1841 & 70 & 1858 & 34 \\ 1842 & 11 & 1859 & 22 \\ 1843 & 1 & 1860 & 27 \\ 1844 & 3 & 1861 & 53 \\ 1845 & 4 & 1862 & 22 \\ 1846 & 5 & 1863 & 5 \\ 1817 & 7 & 1864 & 26 \\ 1818 & 11 & 1865 & 35 \\ 1849 & 69 & 1866 & 59 \\ 1850 & 82 & 1867 & 63 \\ 1851 & 43 & 1868 & 94 \\ 1852 & 118 & 1869 & 22 \\ 1853 & 16 & 1870 & 5 \\ 1854 & 184 & 1871 & 29 \\ 1855 & 151 & 1872 & 41 \\ 1856 & 17 & 1873 & 3\end{array}$

Cundro 3b. Número de emigrantes en cadena por año

$\begin{array}{lrrr}\text { Año } & \text { Nüm. } & \text { Año } & \text { Nüm. } \\ 1810 & 8 & 1857 & 7 \\ 1811 & 1 & 1858 & 4 \\ 1812 & 8 & 1859 & 1 \\ 1813 & 3 & 1860 & 3 \\ 1811 & 3 & 1861 & 3 \\ 1815 & 3 & 1862 & 5 \\ 1846 & 5 & 1863 & 5 \\ 1817 & 1 & 1864 & 9 \\ 1848 & 3 & 1865 & 14 \\ 1819 & 28 & 1866 & 15 \\ 1850 & 21 & 1867 & 1 \\ 1851 & 3 & 1868 & 3 \\ 1852 & 19 & 1869 & 2 \\ 1853 & 5 & 1870 & 0 \\ 1851 & 22 & 1871 & 0 \\ 1855 & 11 & 1872 & 1 \\ 1856 & 7 & & \end{array}$


9732 habitantes en $1857^{52}$ a 8627 en 1887.53

Si se toman algunas localidades aisladas, por ejemplo Arizcun y Lecároz, interesantes por su ubicación dentro del valle como también por el número de emigrados, ${ }^{54}$ cuando el número de emigrantes es determinado por la declaración de "Ir a... donde está tal familiar", resulta reducido; pero cuando surge de la cantidad de personas por grupos de apellidos repetidos aumenta. La declaración ante el notario debe tomarse con cautela.

Está claro que muchos de los que declararon ir a trabajar, hacer fortuna, o a la aventura, también contaban con familiares en América, pero no lo declararon al notario. Esto bien puede significar que se trasladaban a donde sus conocidos habían progresado, y no a progresar bajo la protección de un conocido.

\section{CONCI.USIONES}

Desde el éscenario expulsor, guardando recaudos analíticos y tomando una región particular, no resulta imposible observar el uso de la cadena. En el caso vasco-español -observados los 1858.

52 Censo de la Población de lispaña, Madrid,

5.3 Junta Provincial del Censo de Población, Madrid, 1887.

5.4 Los números de emigrados son: Arizcun: 235; Elizondo: 182; Irurita: 137; lirrazu: 1/6; lecároz: 110; Arrayoz: 99; Garzaín: 107; Ciga: 79; Orono\% 65; lilvelea: 76; Almando\%: 40; $4 \%$ pilicucta: 45; Berrocta: 43; Aniz: 23; Maya: 61; Urdax: 32; Zugarramurdi: 仵 ficta clel Valle: 78. navarros, guipuzcoanos y vizcaínos-, se puede concluir que el uso del mecanismo fue importante. Los números avalan -si aceptamos que ir al encuentro de alguien significaba ayuda material-el segundo subtipo señalado por los MacDonald (inmigración en serie de trabajadores merced a la ayuda de otros trabajadores aislados ya establecidos), ${ }^{55}$ seguido de migración a través de agentes laborales o padroni, y por último migración de esposas e hijos a unirse con sus maridos. Sin embargo, nos sentimos tentados a opinar -hasta que nuevos trabajos nos desestimen - que acaso sea uno de los mecanismos aislados por Devoto como distinto del propiamente de la cadena: "emigración a través de mecanismos semiespontáneos donde el proceso comienza incentivado por medios de información parentales, paisanos o públicos, pero el movimiento resulta el producto de iniciativas y de recursos de un individuo o de una familia aisladamente" el que mayormente contribuya a reflejar lo que sucedió entre los vascos que emigraron hacia 1840/1880.

La sensación que se tiene al observar los movimientos migratorios vascos del siglo pasado, es que cada cual realizaba su esfuerzo individual o familiar para conseguir el pasaje, los fiadores o el equipaje, pero que todos se encontraban inmersos participan-

55 Ir al encuctitro de un hermano o un tio -llamado o no- cra aceptar las reglas propias cle la relación patrón/cmplcado. Inclusive pensamos, retomandes la posibilidad de la ayuda laboral de un patriente, que cron más proclives a discusioncs y problemas que las entabladas con un desconocido. 
Cuadro 4. Relación de población entre 1852/57. Baztán

$\begin{array}{lr}\text { Pueblo } & 1852 \\ & \\ \text { Almandóz } & 362 \\ \text { Aniz } & 159 \\ \text { Arizcun } & 1674 \\ \text { Azpilicueta } & 575 \\ \text { Berrueta } & 317 \\ \text { Ciga } & 587 \\ \text { Elizondo } & 1358 \\ \text { Elvetea } & 341 \\ \text { Garzaín } & 503 \\ \text { Irurita } & 1070 \\ \text { Lecároz } & 618 \\ \text { Oronoz } & 465\end{array}$

$\begin{array}{rr}1857 & \text { Balance } \\ 402 & +40 \\ 176 & +16 \\ 1471 & -203 \\ 549 & -26 \\ 327 & +10 \\ 522 & -65 \\ 1455 & +87 \\ 389 & +48 \\ 471 & -32 \\ 1052 & -18 \\ 620 & +2 \\ 481 & +16\end{array}$

do de una sensación colectiva. ${ }^{56}$ Esta red, formal e informal a la vez, de información y averiguación de trámites que lo invadía todo en las aldeas y del que nadie podía escapar, seguramente tuvo un efecto demasiado importante para que el marco teórico -mayormente aceptado- sobre la emigración en cadena se justifique aisladamente como concepto.

56 En la región vascofrancesa esta sensación ha quedado reflejada a lo largo de todo el periodo. En 1842, P. Barrete, Emigration, 1842, comentaba que "el lenguaje profetizado por los agentes promueve el espíritu de la imaginación; es ese espíritu de vértigo que aún conforma la epidemia de la emigración". En 1858, los informes del director del departamento de los Pirineos Atlánticos al ministerio correspondiente (Informe 1' Conseil General, Pau) reflejan los "llamados y envíos incesantes de los emigrados en América hacia sus compatriotas". Aún en 1886, Etcheverry, "Basques", 1886, muestra, de acuerdo a los reportes presentados por el Director de B. Pirineos al Ministerio del Interior sobre el movimiento de emigrantes, cómo "los primeros emigrantes seducen a sus compatriotas quedados en el suclo natal por los sucesos obtenidos del otro lado del Atlántico".
Una diferencia teórica, a nuestro entender sustancial, radica en los distintos conceptos sobre la ayuda recibida por los migrantes. Si la información $^{57}$ recobra la importancia que creemos que tuvo en la elección del lugar de destino, pero sobre todo en la traumática decisión de abandonar el lugar natal, el modelo de los MacDonald contribuye poco -o mucho, si se lo entiende como motor para el resto-a explicar el fenómeno inmigratorio vasco decimonónico a la Argentina. Buscar la explicación de la confianza en abandonar Euskadi en algo tan difuso - pero no irreal- como la información, no necesariamente implica alejarnos del enfoque antropológico que busca la teorización de modelos de cadenas. Quizá todo lo contrario. Aquella especie de reaseguro

57 Resulta dificil imaginar el ambiente cotidiano de pueblo vasco en 1860 , totalmente desprovisto de rumores, comentarios e información concreta de lo que sucedía en los otros pueblos. 
(que no figura sino tangencialmente en las fuentes) que animaba y guiaba a los que marchaban "desamparados" ocupó tanto espacio e importancia en la realidad histórica de los vascos que se intenta recuperar, como los llamados concretos de familiares del modelo clásico en cuestión.

Cuadro 5. Emigrados de dos localidades del valle de Baztán a Buenos Aires o Montevideo. 1840/1879

\section{Arizcun}

Total emigrados

Buenos Aires/Mont.

Apellidos repetidos

Declaran "llamado"

\section{Lecároz}

Total emigrados

Buenos Aires/Mont.

Apellidos repetidos

Declaran "llamado"

Fuente: Elaborado con base en Protocolos Notariales publicados por Idoate, Emigración.

\section{BIBLIOGRAFIA}

-Archivos de Guernica. Estadística de interrogación sobre emigración de los pueblos de Vizcaya.

-Azcona, J. M., "En torno a las causas que favorecieron la emigración vasca al Río de la Plata entre 1825 y 1914", Estudios de Geografía e Historia, Bilbao, 1988.

-Baily, Samuel, "La cadena migratoria de los italianos a la Argentina. Los casos de los agnoneses y siroleses" en F. Devoto y G. Rosoli (comps.), La inmigración ita- liana en la Argentina, Ed. Biblos, Buenos Aires, 1985.

, "Cadenas migratorias de italianos a la Argentina: algunos comentarios", Estudios Migratorios Latinoamericanos, núm. 8, Buenos Aires, Tabril, 1988.

_- "Patrones de residencia de los italianos en Buenos Aires y Nueva York, 1880/1914", Estudios Migratorios Latinoamericanos, núm. 1, Buenos Aires, 1985.

-Baines, Dudley, Migration in a Matures Economy, emigration and internal migration in England and Wales, 1861-1900, Cambridge University Press, 1985.

-Barrere, Paul, Emigration a Montevtdeo et a Buenos Aires, Imp. Vignancour, Pau, 1842.

-Censo de la población de España. Según recuento verificado el $21 / 57$ por la Comisión de Estadística General del Reino, Imprenta Nacional, Madrid (1858).

Censo municipal de la ciudad de Buenos Aires, 1855, Archivo General de la Nación.

-Devoto, F. y G. Rosoli (comps.), La inmigración italiana en la Argentina, Ed. Biblos, Buenos Aires, 1985.

-Devoto, Fernando, Estudios Migratorios Latinoamericanos, núm. 8, Buenos Aires, 1988, presentación.

, "Las cadenas migratorias italianas: algunas reflexiones a la luz del caso argentino" Estudios Migratorios Latinoamericanos, núm. 8, Buenos Aires (1988).

-Douglas, W., y J. Bilbao, Amerika. nuak. Los vascos en el nuevo mundo, Ed. U.P.V., Bilbao, 1986.

-Etcheverry, L., "Les basques et leurs emigration en Amérique", Reformes Sociales, núm. XI, París, 1886.

-Gallego, José A., Historia contemporánea de Navarra, Pamplona, 1982.

-Garaico Echea, A. 1., De Vasconia a Buenos Aires, Ed. Ekin, Buenos Aires, 1945. 
-Garciarena, J. M., Cartas de Tierra Adentro, Ed. Ekin, Buenos Aires, 1977.

-Idoate Ezquicta, Carlos, Emigración navarra del valle de Baztán a América en el siglo $X I X, 1989$, Depto. Educación y Cultura, Pamplona, 1989.

-Iriani, Marcelino, "Como en nuestra casa... Fondas y hoteles vascos en la pro. vincia de Buenos Aires. 1840/1940", Siglo $X I X$, Instituto Mora, México, 1993.

-, "Los vascos en el siglo XIX. América en sus planes", Siudi Emigrazione, núm. 14, Roma, 1994.

-Junta Provincial del Censo de Población, Madrid, 1887.

-Lhandé, Pierrc, L'emigration basque, París, 1909.

-Mac Donald, John, "Chain migration, cthnic neigbourhood formation, and social networks", Milbank memorial fund quarlerly, núm. 42, 1964 .

-Otero, Hcrnán, "La inmigración francesa en Tandil. Un aporte metodológico para cl estudio de las migraciones en demografia histórica", Desarrollo Económico, núm. 125, abril/junio 1992.

-Pildain Salazar, Pilar, "Ir a América. La emigración vasca a América, Guipúzcoa,
1840/70", conversaciones, Euzkadi, octubre/novicmbre, 1991.

-Price, Charles, Southern europeans in Australie, Melbourne, Sidney, 1983.

-Silberstain, Carina, "Inmigración y selección matrimonial: El caso de los italianos en Rosario 1870/1910", Estudios Migratorios Latinoamericanos, núm. 8, Bucnos Aires, 1988.

-Sturino, Franc, "Emigración italiana: reconsideración de los eslabones de la cadena migratoria", listudios Migratorios Latinoamericanos, núm. 8, Buenos Aires, 1988.

-Torassa, Antonio, El partido de Avellaneda, 1580/1890, A.1H.P.B.A., La Plata, 1940.

-Vicrs, George, "Chronique: les basques et l'Amcrique", Revue Geographique des Pyrenées, núm. 28, 1957.

-Virto Ibáñcz, Juan, "La cmigración de navarros hacia $\Lambda$ mérica en la segunda mitad del siglo XIX", Fstudios de Ciencias Sociales, núm. 4, U.N.E.D., Pamplona, 1991.

-Weimberg, F. y A. S. Ebcrle, "Los abruzeses en Bahía Blanca. Estudio de cadenas migratorias", Estudios Migratorios Latinoamericanos, núm. 8, 1988. 